\title{
ACE factor deficiency theory
}

\author{
Alaa Abdelkarim* and Fouad Alaa \\ ACE Cells Lab Limited, UK
}

There are more than 300 theories that explain aging and anti-aging. Most of the Chinese medicine doctors and the homeopathic doctors created theories, and each according to their own vision and experience. Some theories were created to promote certain products and some were only to get some fame. On the other hand, the western medicine focused more on the pathogenesis and explanation of the diseases. The etiology occupied the main portion of their researches that explain the diseases and try to find their cures. No doubt, it is very important to know the etiology and to use it to be able to get the proper treatment.

Imagine a city that was subjected to three different types of catastrophes, an earthquake, a tornado and a typhoon. The objective here is to rebuild this city and to restore its function. Knowing the general cause of the destruction will help us to take the proper damage control, but we can't rebuild it depending only on damage control.

For example, if the cause of destruction is nuclear bomb, then continuous survey for the irradiations will help in preventing lots of side of effects in the future, but eventually we need to rebuild the buildings and pave the roads and restore the infrastructure regardless of what type of bomb it is. The cause of the destruction may help in the fine adjustment of the process of rebuilding, but not the general plan of restoring an entire city to its former glory.

When it comes to the general reconstruction plan, there are two types. The first would be a slow but steady plan, in which we provide a systematic reconstruction plan build on small number of resources over a long period of time. The second plan is to provide a massive amount of resources over a condensed period of time.

The first case is risky because the fewer resources one might have the more risk of delay one might get if any resource became faulty. In the second case there would be rapidly expanding renovation and there might be excess in resources once everything is restored

Based on my observations, i noticed the second case happening when it comes to using the peptides and cell therapy applications in either treating diseases or rejuvenation.

Whenever any disease is found, there is a state of mass destruction in the affected area. Regardless of the cause, (which can be inflammation, infection, neoplasm, surgical operation, auto-immune, metabolic or genetic) the affected area suffers from massive destruction. It also would have a sever deficiency in all the anabolic units that can help the cells to regenerate into healthy cells again and the result in most cases is either healing by fibrosis or sclerosis. The cells get sclerotic after a long time of waiting for the needed materials to heal it in a healthy way.

Copyright: $(02017$ Abdelkarim A. This is an open-access article distributed under the terms of the Creative Commons Attribution License, which permits unrestricted use, distribution, and reproduction in any medium, provided the original author and source are credited.
Some of these elements are essential elements that can't be synthetized in the body, and some of them can be found in animal or plant source from which the patient doesn't consume. Consider the following equation as an example:-

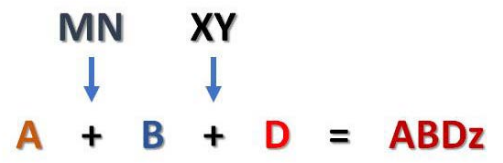

$\mathrm{ABDz}=$ one of the elements that the cell needs in its regeneration.

$\mathrm{A}=$ normal element present in most of the dietary components.

$\mathrm{B}=$ Essential element can be found only from animal source.

$\mathrm{D}=$ Essential element can be found only in plant source.

$\mathrm{MN}=$ essential enzyme

$\mathrm{XY}=\mathrm{Co}$ factor.

In this equation $\mathrm{ABDz}$ can be synthetized when $\mathrm{A}$ interacts with $\mathrm{B}$ in the presence of $\mathrm{MN}$ and the result combine with $\mathrm{D}$ in the presence of XY. It is quite logical to deduce that the absence of any one of these elements will lead to $\mathrm{ABDz}$ deficiency syndrome. The only way to have $\mathrm{ABDz}$ is to have all the elements together so that we restore the synthesis of ABDz. When the cells are damages not only $\mathrm{ABDz}$ is deficient, but also all the other biological anabolic block are deficient. Therefore, supplying all the needed elements in enough amounts will lead to restoration of the normal structure of the cell and hence the physiological function.

Searching for a specific factor or supplying specific factor might be successful only in case that all other elements are present. Therefore, we find limited success for the researches that focus on supplying one element as its deficiency is the etiology of the disease.

Sometimes this factor is not well known. And to rejuvenate the cells we do not know which factor that is deficient as it might be variable according to the patient's life style and the dietary habits. This is why we call it the ACE factor, the factor(s) which we do not know in specific but we know that there are several deficient factors. Those several deficient factors are the ACE factor which contains all the needed factors to enable the regeneration in proper and fast way.

At ACE theory our vision is not only to control the damage but to go after its source, the restoration to the original state and eradication of the source regardless of the cause.

Correspondence to: Alaa Abdelkarim, ACE Cells Lab Limited, UK, Tel: $+44(0)$ 281444 516; E-mail: dralaakarim@gmail.com

Received: November 20, 2017; Accepted: December 14, 2017; Published: December 17, 2017 